\title{
Using Movie Clips to Help Teach Accounting Principles
}

\author{
Tim Creel \\ Lipscomb University
}

\author{
Veronica Paz \\ Indiana University of Pennsylvania \\ Kelli Horne \\ Lander University
}

\begin{abstract}
Movie clips are a useful way to illustrate accounting principles in managerial or cost accounting along with auditing classes. They promote a fun learning environment and student engagement when faculty discusses how the clip illustrates a specific accounting concept. At the discretion of the Professor, movie clips illustrate the concept before or after a presentation to the class. Many found the use of video clips helped students retain the information. Movie clips illustrate managerial or cost accounting concepts such as ethics, the balanced scorecard, budgeting, process re-engineering, selling or processing further, quantitative and qualitative analysis, internal controls, value, and non-value-added activities, continuous improvement and sustainability. Movie clips illustrate auditing concepts such as ethics, learning business operations, internal controls and collusion. Also, video clips address student motivation as part of promoting a fun learning environment in the accounting classroom.
\end{abstract}

\section{INTRODUCTION}

The use of movie clips in an accounting classroom helps promote and emphasize accounting concepts. They provide a fun, interactive and engaging classroom experience for students. This paper examines movie clips used to illustrate management or cost accounting concepts such as the Balanced Scorecard, ethics, budgeting, process re-engineering, selling or processing further, quantitative and qualitative business decisions, internal controls, value and non-value-added activities, continuous improvement and sustainability. Movie clips display auditing concepts such as internal controls, ethics, collusion, and learning business operations. Movie clips address student motivation as well as accounting topics. The video clips display accounting concepts from managerial and cost accounting classes along with auditing at both the undergraduate and graduate levels.

This paper differentiates itself by offering many movie clips that can be used in different classes, but also discusses ways for faculty to show the clips in the appendix. Faculty can choose to show them to introduce an accounting concept or they can choose to show them afterwards to reinforce an accounting concept. 


\section{LITERATURE REVIEW}

Movie clips are a useful way to help illustrate concepts in an accounting classroom. Science and economics classes discussed the use of movie clips to illustrate various ideas and even included problemsolving related to the clips. After showing movie clips, the professor can engage the students in how the clip related to an important concept taught in the class as the video clips promote interaction with the students. They provide a fun learning experience and a strong visual example for learners. Movie clips promote strong learning experience for many students.

Literature shows film clips presented in science and economics classes. One example is from Blickenstaff (2011) as the professor used movie clips in science and physics classes both to illustrate points, but also to promote problem-solving skills with the students. An example used in the article showed a clip from Spiderman 2 where Spiderman stops a train with his web. The professor then asked the students to find the average force necessary to stop the train. The students' answers varied, but it was a great exercise to promote student engagement, original thought and interest in the subject. Sexton (2006) used movie clips to promote economic concepts. For example, he used a clip from the Shawshank Redemption to illustrate the economic concept of exchange. He did this to break up the lecture and found it helped the students keep and retain the information within the clips.

Using movie clips in an accounting classroom promotes engagement with the students and an interactive environment. This offers great opportunity to discuss the clip and how it relates to an accounting concept. Robinson and Kakela (2006) found interaction in the classroom promoted a personalized approach to learning, encouraged original thought processes, and expanded the boundaries of the class itself. Strage (2008) found the best learning environment for students as one with engagement, effective instructional methods, and applications related to the real world.

The use of movie clips in an accounting classroom not only promotes interaction and engagement with students, but it creates a fun learning environment. Classroom activities that promote involvement among the students and those with a fun delivery method were found to promote fun in the learning experience (Tews, Jackson, Ramsay, and Michel, 2014). Jarrett and Burnley (2010) found a fun atmosphere in a college classroom promoted student engagement and positive student reactions to the class.

Movie clips promote a robust learning environment for many students. Visual experiences create links to prior knowledge and new or complex ideas (Brisland, 2010). Gill (2011) found students engage the most during video presentations and small group activities, but the students reported the most valuable learning activities were video presentations and lecture. Visual learning styles benefit from the use of movie clips to illustrate accounting concepts as research shows learning outcomes improve when matched to a student's cognitive style (Thomas and Mckay, 2010).

\section{MOVIE CLIPS}

The use of video clips in an accounting class adds to the student experience of learning accounting principles. It creates a fun learning environment and allows interaction between students and faculty members. Video clips are useful in management and cost accounting classes along with auditing at both the undergraduate and graduate levels. Student motivation is an effective use of movie clips in the classroom. Management and cost accounting principles re-illustrated in movie clips such as budgeting, process re-engineering, the manufacturing process, ethics, sell or process further, quantitative business decisions, internal controls, qualitative business decisions, value-added and non-value-added activities, continuous improvement, sustainability, and the balanced scorecard. Auditing principles such as internal controls, collusion, ethics, learning about the operations of a company, and forensic accounting re shown in movie clips. 


\section{Student Motivation}

No professor wants their class to operate like Ben Stein's history class in Ferris Bueller's Day Off with most of the students asleep.

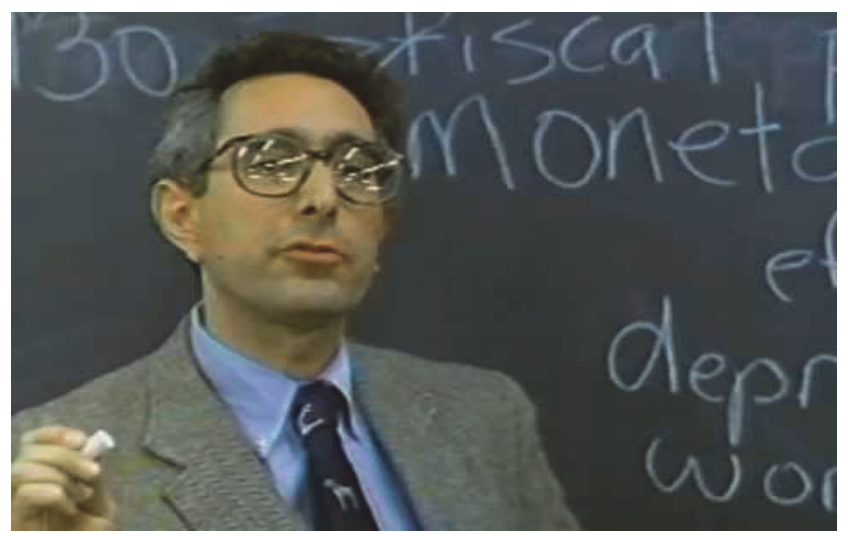

Movie clips help motivate students such as the speech from Braveheart. This a great clip to show right before a test or right after the students return from a break.

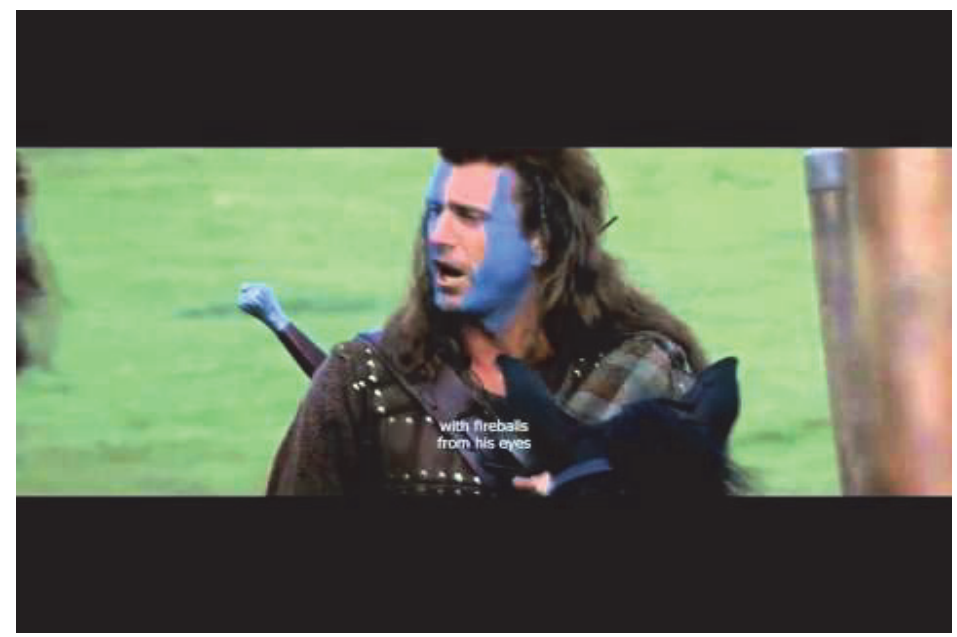

In the movie Rudy, the star finally gets to play in his last game with Notre Dame and sacks the quarterback on the final play of the game after years of playing on the practice squad. This video clip illustrates never giving up on dreams of success.

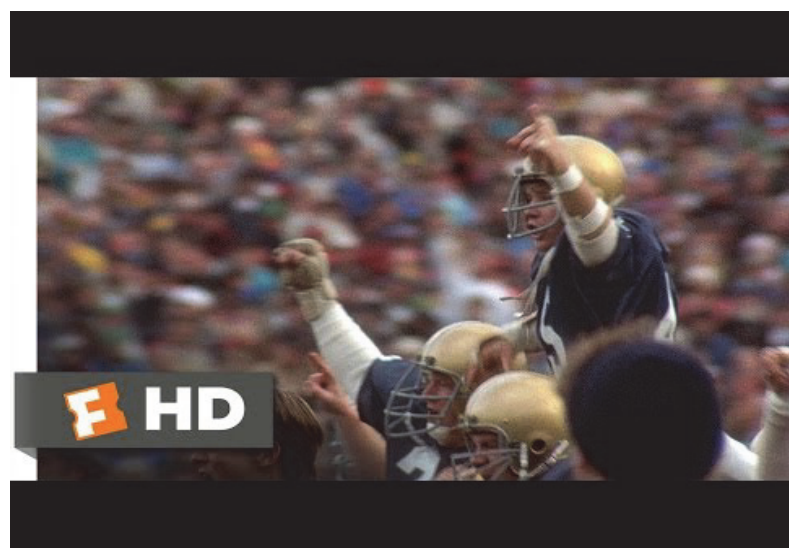


In the movie Rocky, Rocky was an unknown fighter with a shot at the championship. This clip shows him running through the streets of Philadelphia training for his title fight.

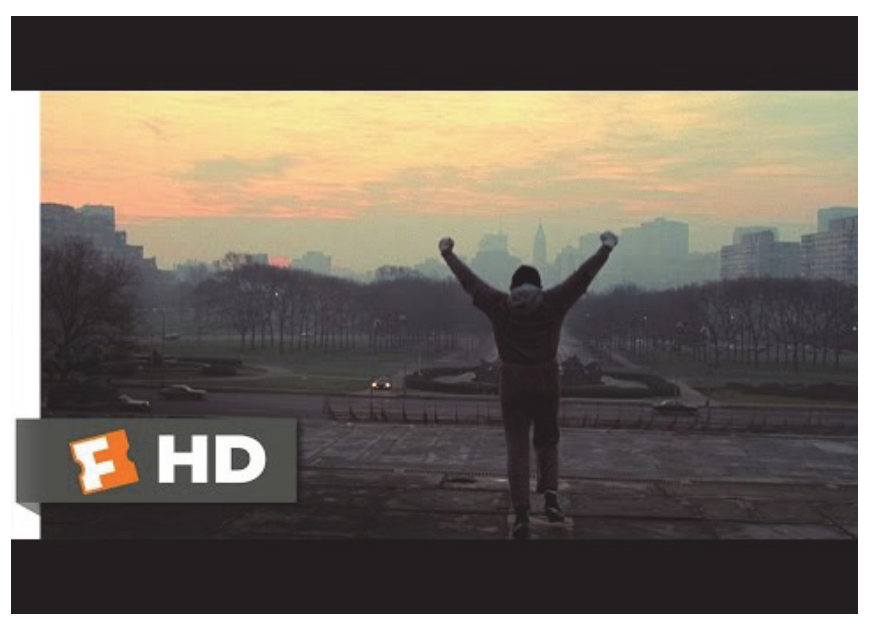

\section{Budgeting}

In the Martian, the astronaut left behind on Mars takes time to perform an inventory to come up with a budget so it will last during his stay. This clip illustrates the planning and control aspects of budgets.

\section{Process Re-engineering}

In The Martian, the astronaut discovers how to grow potatoes on Mars through bringing in soil and fertilizer along with water. The act of creating new ways to accomplish this undertaking illustrates process re-engineering which is finding new and better ways to produce a product.

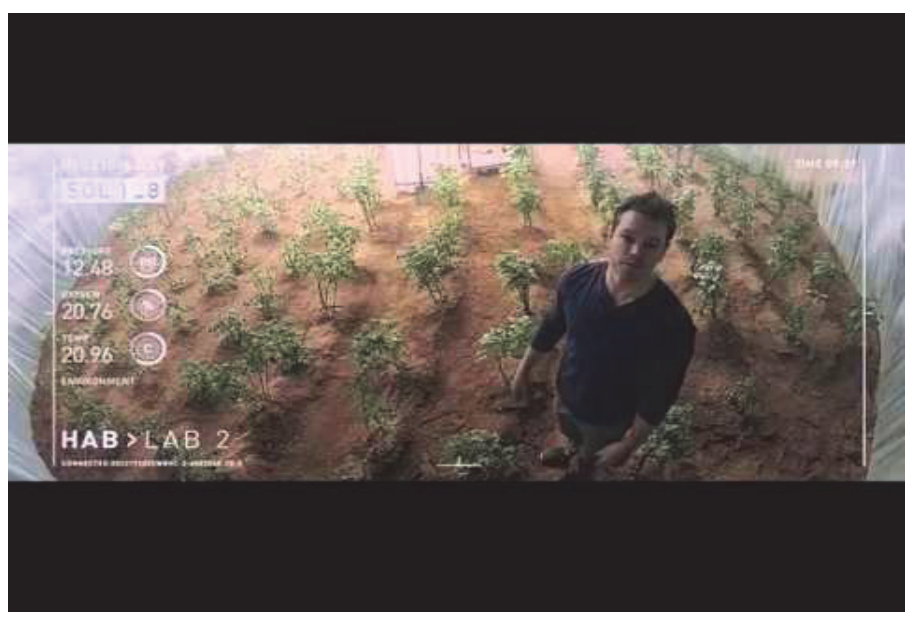

\section{Ethics}

In the movie, Wall Street, Michael Douglas's character states that "greed is good" in his speech to shareholders. This clip can be used to start an interesting discussion about ethics and tone at the top of an organization. 


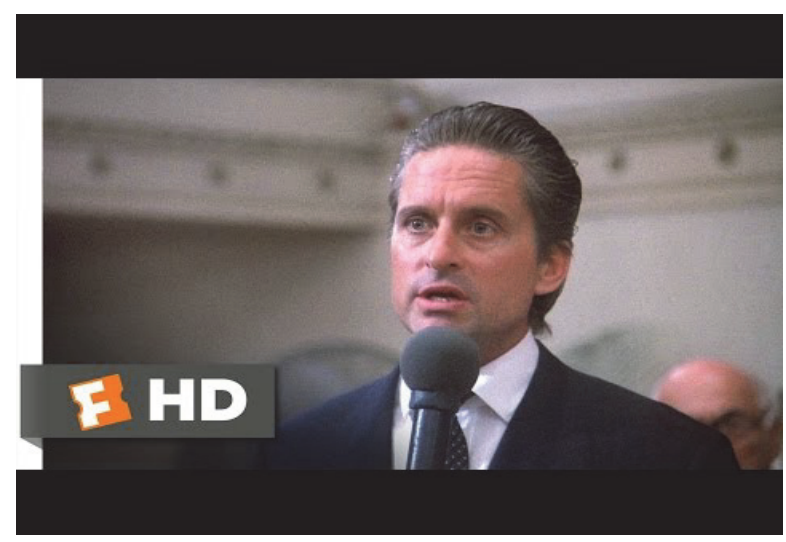

The following movie clip from The Smartest Guys in the Room examines the definition of wrong concerning the Enron scandal. It shows real-world examples of how employees were affected by the scandal at Enron.

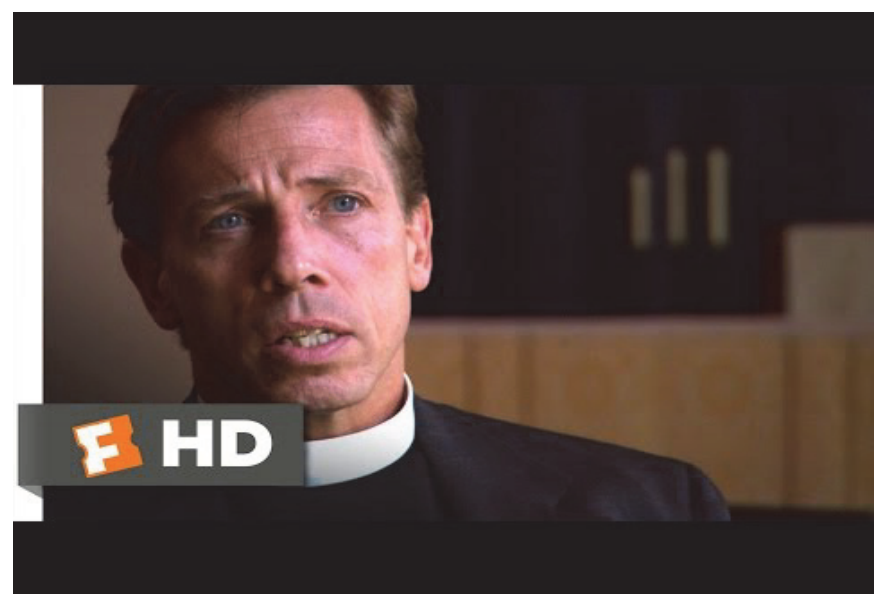

\section{Sell or Process Further}

In the movie Amadeus, a leading musician composes a song for Mozart. Mozart takes the composition, and immediate adds to it and makes improvements. This movie clip illustrates the idea of selling or processing further as a company must choose to sell a product or process it further if it generates higher profits.

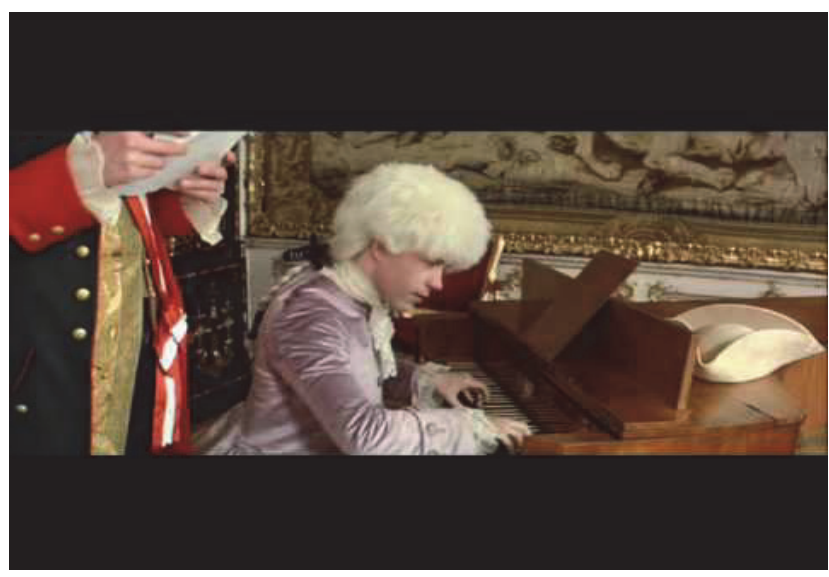




\section{Quantitative Business Decisions}

In the movie Moneyball, the Oakland A's start using mathematical formulas to find the best players for their team within their budget constraints. Quantitative numbers are part of an examination of business decisions. This clip illustrates the importance of factoring in the numbers into business decisions such as make or buy decisions or shutting down an unprofitable product or segment.

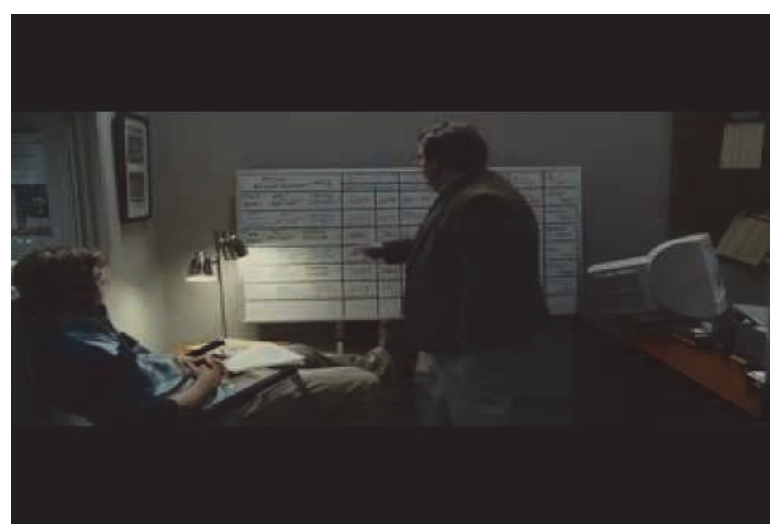

\section{Internal Controls}

In the movie Mission Impossible: Ghost Protocol, Tom Cruise must get information by breaking into a computer center on a very high floor of the world's tallest building. This clip illustrates the importance of having strong, physical internal controls in place in a business.

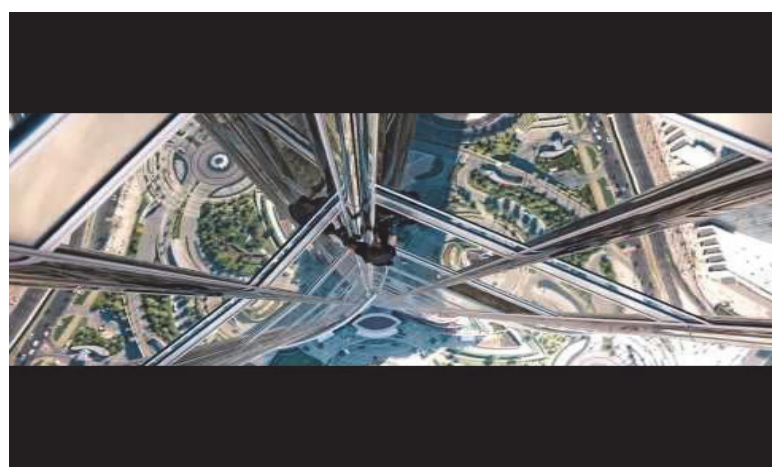

Other clips from Mission Impossible movies can be used as an example of internal controls as well such as in Rogue Nation where they must get information out of a highly protected building with their computer system underwater.

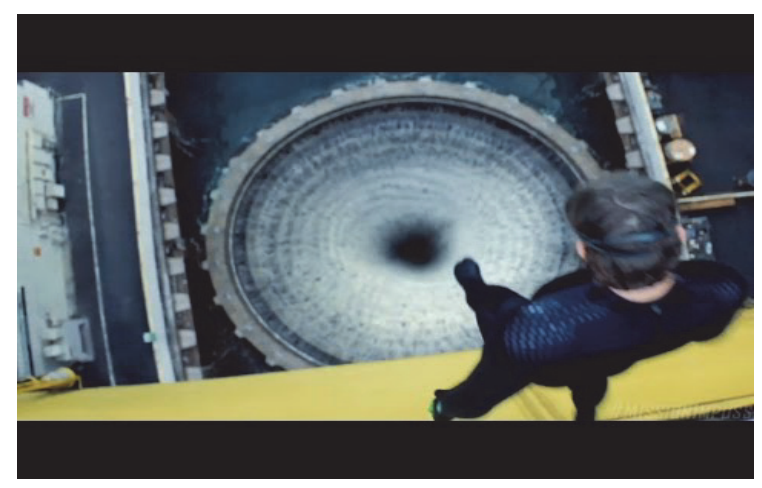




\section{Qualitative Business Decisions}

In the movie, Skyfall, James Bond is tested to be able to return to active duty. He fails the tests, but the head of MI6 still allows him to return to service. This clip illustrates examining the qualitative aspects of business decisions and not just looking at the numbers alone. The movie clip relates to make or buy decisions, special orders, or shutting down an unprofitable product or segment.
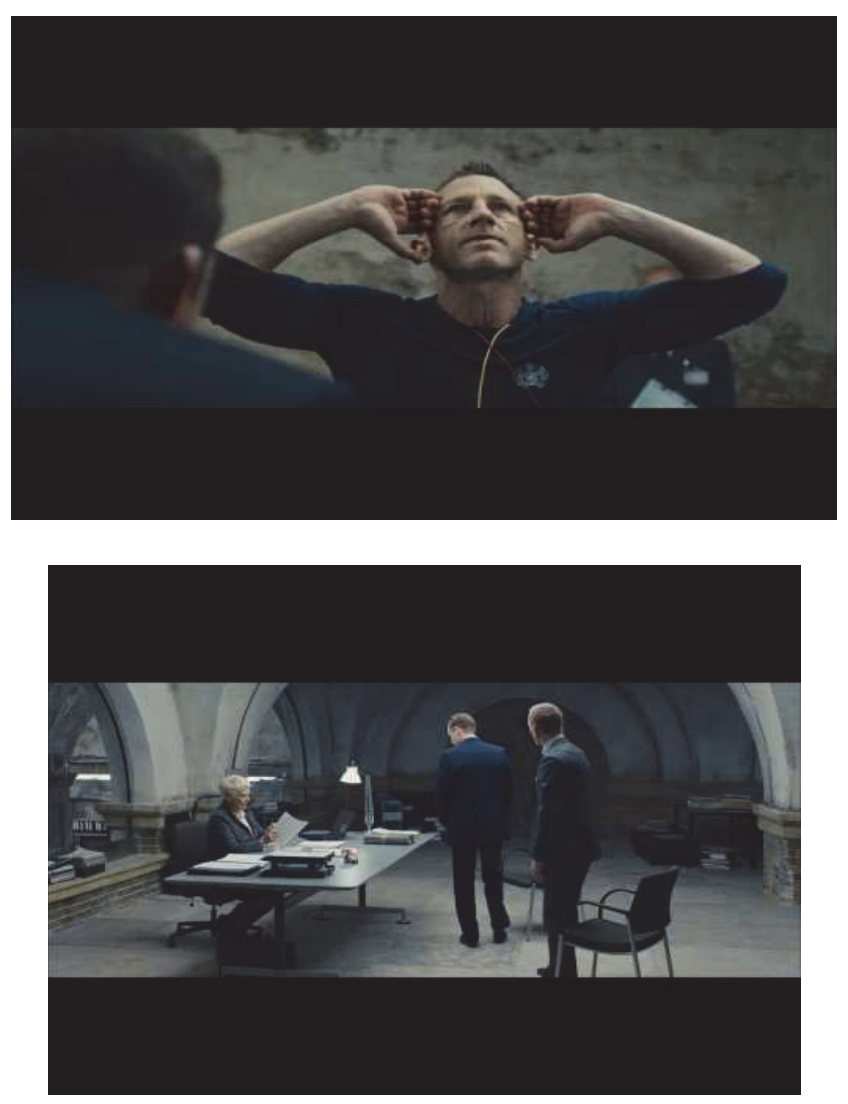

\section{Value-added and Non-value-added Activities}

In The Aviator, Howard Hughes develops a test aircraft built for speed called the H-1. The builders take out the bumps from the rivets in order to lessen the drag and increase speed. The bumps from the rivets were a non-value-added activity and taken off the plane. The movie clip illustrates to students an organization's desire to remove non-value-added activities from their products or services.

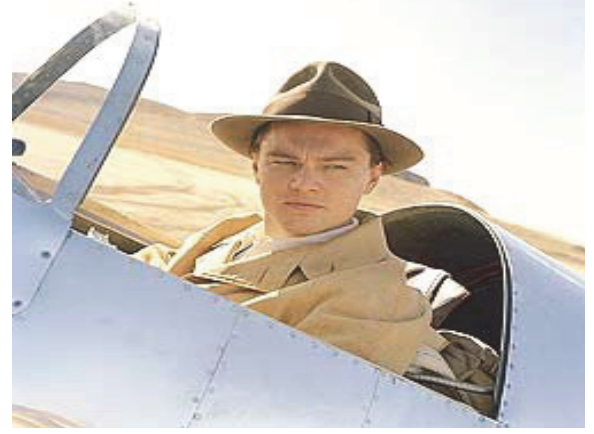

In Pearl Harbor, Doolittle prepares his squads planes to undertake a surprise bombing of Tokyo early in World War II. They remove many items from their planes to make them lighter so they can reach Tokyo. The things they removed were non-value-added items while the pilots, gas, and bombs were 
value-added activities. This clip shows students that companies must identify what is value-added and non-value-added and eliminate the non-value-added items.

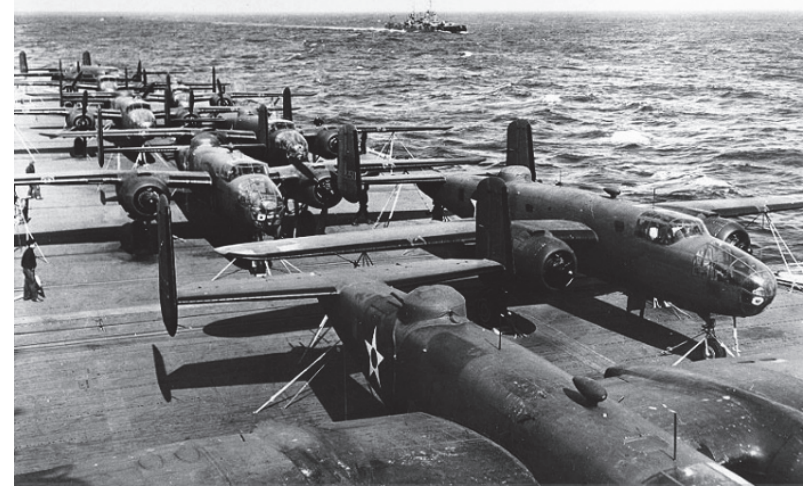

\section{Continuous Improvement}

In the movie Ironman, Tony Stark developed the Ironman suit. It was very basic at first but keep on improving over time. These clips show students that companies may implement a policy where they continuously make improvements to their products, services or processes.
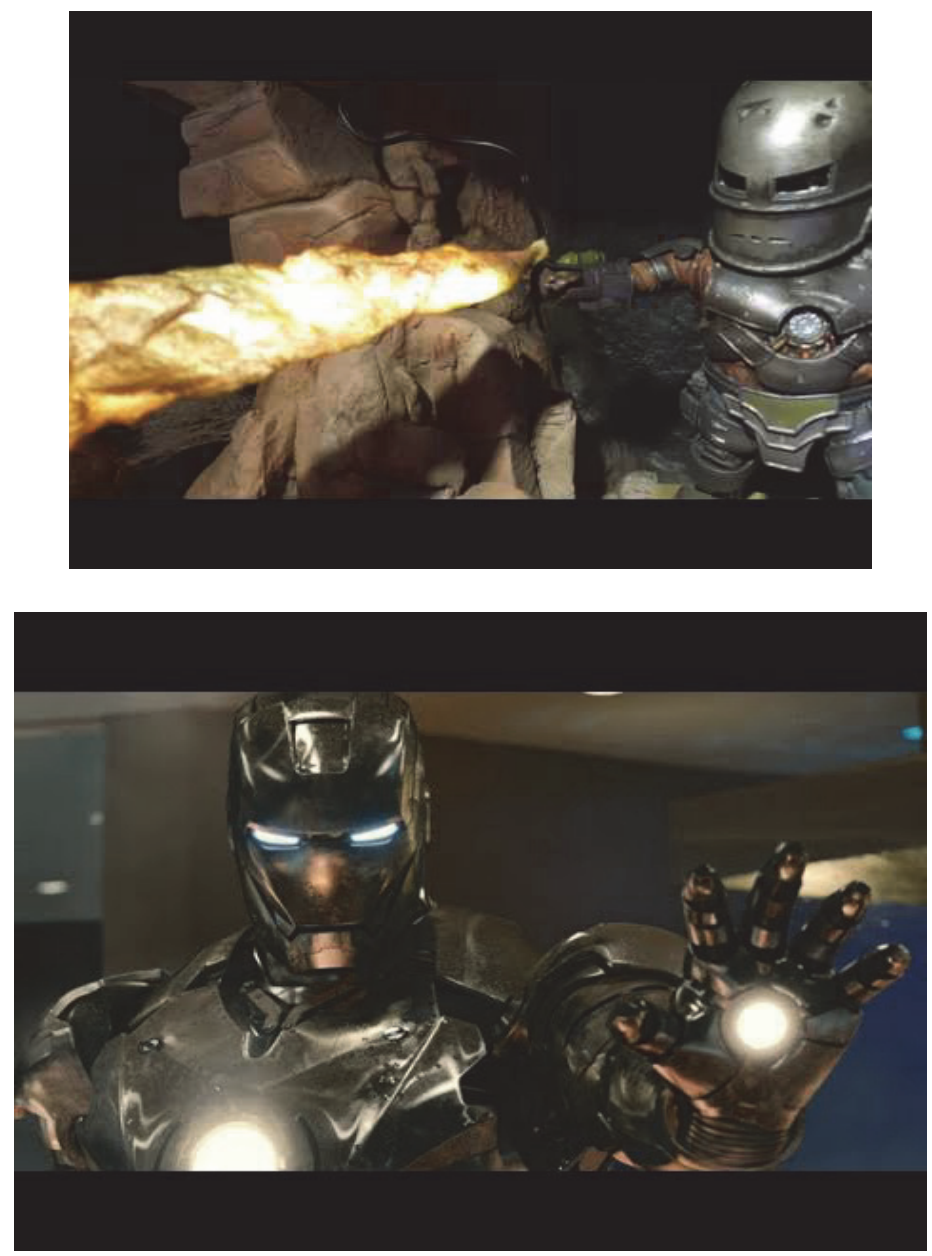

126 Journal of Accounting and Finance Vol. 19(8) 2019 


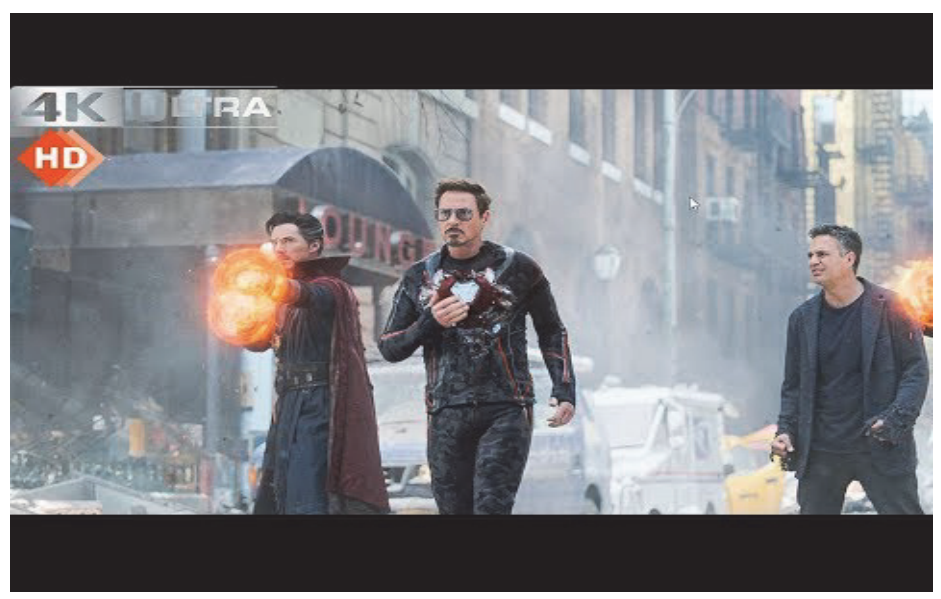

\section{Sustainability}

In Man of Steel, the planet Krypton attains their energy from the Planet's core due to using up all other sources. This scene at the start of the film illustrates long-term sustainability costs due to the fact they did not use their energy sources wisely. This activity eventually destroyed their planet. This movie clip could start a discussion of how business must maintain sustainability standards.

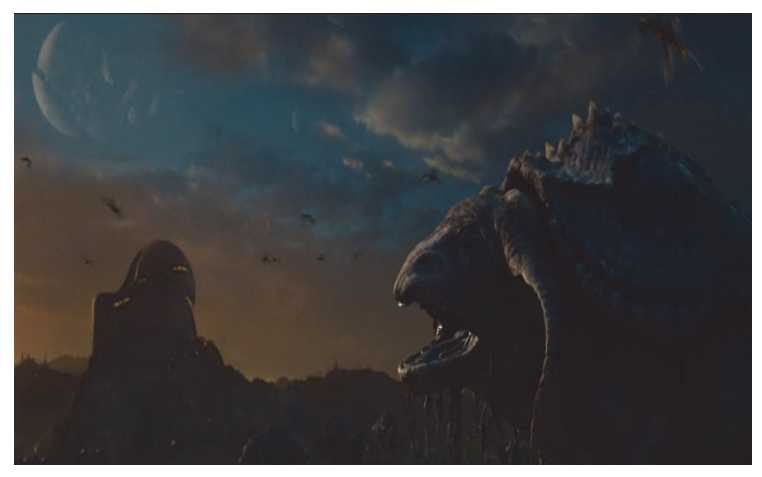

\section{The Balanced Scorecard}

In The Empire Strikes Back, Yoda trains Luke in the ways of becoming a Jedi. Yoda asks Luke to move his ship out of the water and states "I will try." Yoda's reply is legendary when he says, "do or do not, there is no try." This idea is true of a successful implementation of the Balanced Scorecard as it takes considerable effort for it to be successful. There is no "try" in the successful implementation of the Balanced Scorecard.

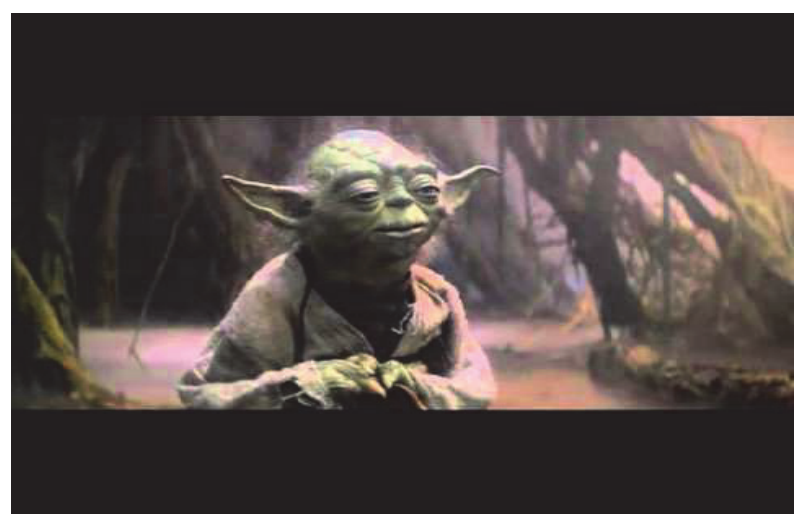




\section{Collusion}

The following clip from Office Space illustrates how employees can work together to get around internal controls set up by the company. Many internal controls may be established to stop one employee from breaking the rules, but different employees working together may get around the controls.

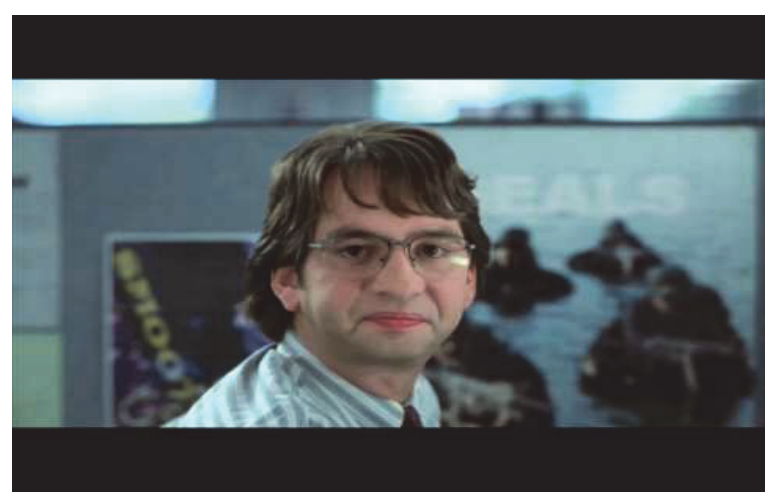

\section{Learning About How a Company Operates}

The following movie clips from Office Space illustrate how auditors learn about the operations within a company. These clips show how an interview can be used by auditors to learn what employees do as part of their jobs.
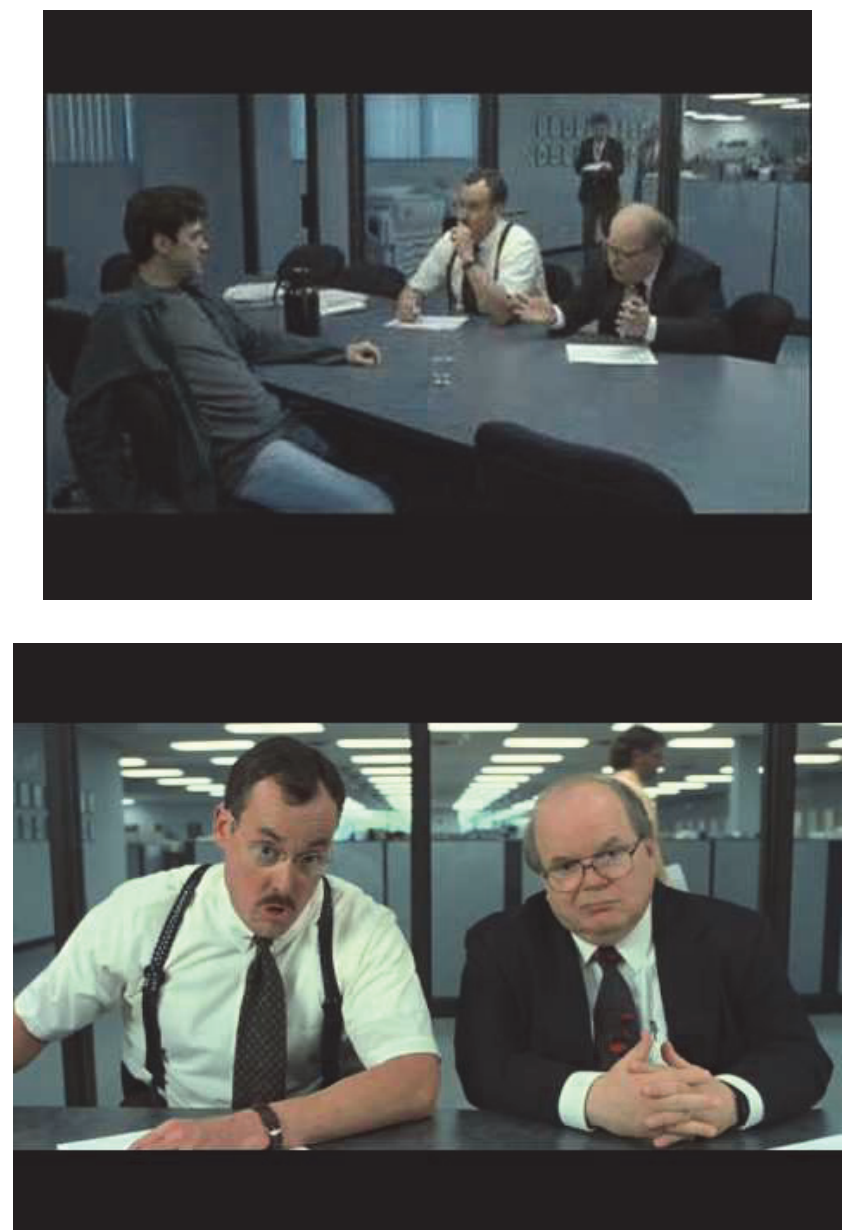


\section{Forensic Accounting}

In the following movie clip from The Accountant, forensic accounting displays his process of searching for missing funds. A professor could also point out how different aspects of artificial intelligence or data analytics could be used by an auditor to solve a problem like this one today.

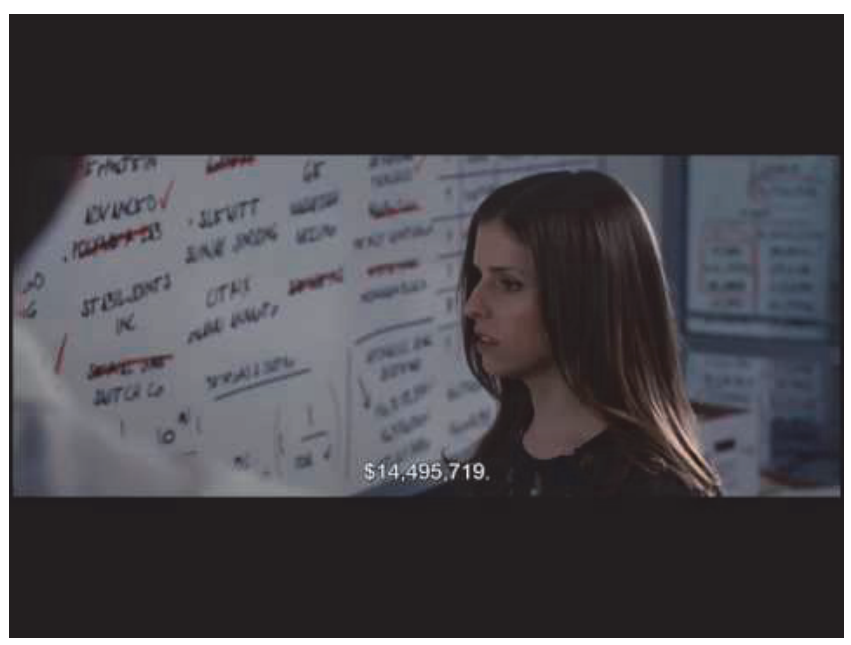

\section{CONCLUSION}

Movie and video clips are a great way to reinforce management and cost accounting and auditing concepts in both undergraduate and graduate courses. They promote a fun learning environment with student engagement and interaction with the professor discussing aspects of the movie clip concerning specific accounting concepts. Movie clips illustrate management and cost accounting concepts such as the Balanced Scorecard, ethics, budgeting, value, and non-value-added activities, selling or processing further, process re-engineering, sustainability, quantitative and qualitative decisions, and internal controls. Many of the same clips used in managerial or cost accounting relate to auditing classes such as ethics and internal controls along with clips about collusion, learning about the operations of a company, and forensic accounting. Some movie clips promote student motivation in the classroom.

\section{REFERENCES}

Abrams, J.J. (Producer), \& Bird, B. (Director). (2011). Mission Impossible: Ghost Protocol. United States: Paramount Pictures.

Abrams, J.J. (Producer), \& McQuarrie, C. (Director). (2015). Mission Impossible: Rogue Nation. United States: Paramount Pictures.

Arad, A., Feige, K. (Producers), \& Favreau, J. (Director). (2008). Ironman. United States: Paramount Pictures.

Bakshi, M. (Producer), \& Miller, B. (Director). (2011). Moneyball. United States: Sony Pictures Blickenstaff, J. (2011). I'll Bring the Popcorn. The Science Teacher, September 2011, 42-46.

Brigham, C. (Producer), \& Scorsese, M. (Director). (2004). The Aviator. United States: Warner Brothers.

Brisland, B. (2010). Another way of knowing: Visualizing the ancient silk routes. The Social Studies, 101(2), 80-86.

Bruckheimer, J. (Producer), \& Bay, M. (Director). (2001). Pearl Harbor. United States: Touchstone Pictures.

Caracciolo, J.M. (Producer), \& Raimi, S. (Director). (2004). Spiderman 2. United States: Columbia Pictures.

Chartoff, R. (Producer), \& Avidsen, J.G. (Director). (1976). Rocky. United States: United Artists. 
Fiege, K. (Producer), Russo, A. \& Russo, J. (Directors). (2018). Avengers:Infinity War. United States: Marvel Studios.

Fried, R.N. (Producer), \& Anspaugh, D. (Director). (1993). Rudy. United States: Tristar Pictures

Gibney, A. (Producer \& Director). (2005). The Smartest Guys in the Room. United States: Magnolia.

Gibson, M. (Producer \& Director). (1995). Braveheart. United States: Paramount.

Gill, R. (2011). Effective Strategies for Engaging Students in Large-Lecture, Non-majors Science Courses. Journal of College Science Teaching, 41(2), 14-21.

Howell, L. (Producer), \& O'Connor, G. (Director). (2016). The Accountant. United States: Warner Brothers.

Hughes, J. (Producer \& Director). (1986). Ferris Bueller's Day Off. United States: Paramount.

Jarrett, O., \& Burnley, P. (2010). Lessons on the Role of Fun/Playfulness from a Geology Undergraduate Summer Research Program. Journal of Geoscience Education, 58(2), 110 -120.

Kinberg, S. (Producer), \& Scott, R. (Director). (2015). The Martian. United States: Twentieth Century Fox.

Kurtz, G. (Producer), \& Kershner, I. (Director). (1980). The Empire Strikes Back. United States: Lucasfilm, LTD.

Marvin, N. (Producer), \& Darabont, F. (Director). (1994). The Shawshank Redemption. United States: Castle Rock Entertainment.

Nolan, C. (Producer), \& Snyder, Z. (Director). (2013). Man of Steel. United States: Legendary Pictures.

Pressman, E.R. (Producer), \& Stone, O. (Director). (1987). Wall Street. United States: Twentieth Century Fox.

Robinson, C., \& Kakela, P. (2006). Creating a Space to Learn: A Classroom of Fun Interaction and Trust.College Teaching, 54(1), 202-208.

Rotenberg, M. (Producer), \& Judge, M. (Director). (1999). Office Space. United States: Twentieth Century Fox.

Sexton, R. (2006). Using Short Movie and Television Clips in the Economics Principles Class. Journal of Economic Education, 37(4), 406-417.

Strage, A. (2008). Traditional and Non-traditional College Students Descriptions of the "Ideal" Professor and the "Ideal" Course and Perceived Strengths and Limitations. College Student Journal, 25(1), 225-232.

Tews, M., Jackson, K., Ramsay, C., \& Michel, J. (2014). Fun in the College Classroom: Examining Its Nature and Relationship with Student Engagement. College Teaching, 63, 16-26.

Thomas, P., \& McKay, J. (2010). Cognitive Styles and Instructional Design in University Learning. Learning and Individual Differences, 20, 197-202.

Wilson, M.G. (Producer), \& Mendes, S. (Director). (2012). Skyfall. United States: MGM.

Zaentz, S. (Producer), \& Forman, M. (Director). (1984). Amadeus. United States: Warner Brothers. 


\section{APPENDIX}

When using video clips in the classroom, they can be effectively used three ways: before the lecture to introduce the topic, to start a discussion in place of a lecture, or after a lecture to support the ideas within the lecture. Interaction with the students will take place as part of either method, and the faculty member will want to introduce the students to the movie clip before showing it to the students.

If the professor decides to use it in place of a lecture, they will introduce the video to the students by letting them know about the clip or the background of the scene. After showing the movie clip, the professor would start asking questions of the students about the clip and direct the class toward the points they want the students to learn about the subject. It involves heavy interaction with the students after the clip as it will serve as the principle method along with the discussion with the class to teach the desired topic.

If using before the lecture, the professor would introduce the students to the clip before showing. After showing, they would start into their lecture of the material, and they should tie back some aspects of the clip to their subject matter. If using after the lecture, they would show the clips and use it to reinforce the principles spoken of during the lecture. In either case, they would interact with the students, and they may ask questions. The video clip is an excellent way in either case to reinforce the information shared with students in the lecture.

Most of the video clips can be found in www.youtube.com or by using DVDs of the movies themselves. The following website produced by one of the authors displays links to all of the movie clips within this paper: https://www.drvpaz.com/accounting-teaching-tools. 